\title{
Review
}

\section{Cytoplasmic male sterility in Brassicaceae crops}

\author{
Hiroshi Yamagishi*1) and Shripad R. Bhat ${ }^{2)}$ \\ 1) Faculty of Life Sciences, Kyoto Sangyo University, Kamigamo, Kita, Kyoto 603-8555, Japan \\ 2) National Research Centre of Plant Biotechnology, New Delhi 10012, India
}

Brassicaceae crops display strong hybrid vigor, and have long been subject to $F_{1}$ hybrid breeding. Because the most reliable system of $F_{1}$ seed production is based on cytoplasmic male sterility (CMS), various types of CMS have been developed and adopted in practice to breed Brassicaceae oil seed and vegetable crops. CMS is a maternally inherited trait encoded in the mitochondrial genome, and the male sterile phenotype arises as a result of interaction of a mitochondrial CMS gene and a nuclear fertility restoring $(R f)$ gene. Therefore, CMS has been intensively investigated for gaining basic insights into molecular aspects of nuclear-mitochondrial genome interactions and for practical applications in plant breeding. Several CMS genes have been identified by molecular genetic studies, including Ogura CMS from Japanese radish, which is the most extensively studied and most widely used. In this review, we discuss Ogura CMS, and other CMS systems, and the causal mitochondrial genes for CMS. Studies on nuclear $R f$ genes and the cytoplasmic effects of alien cytoplasm on general crop performance are also reviewed. Finally, some of the unresolved questions about CMS are highlighted.

Key Words: Brassicaceae, cytoplasmic male sterility, mitochondrial gene, $R f$ gene, Ogura CMS.

\section{Introduction}

Among Brassicaceae crops, six Brassica species and Raphanus sativus are cultivated worldwide as oil seed and vegetable crops. It has long been known that these Brassicaceae crops show strong heterosis. Oil seed crops such as $B$. napus and B. juncea show hybrid vigor in terms of seed yield (up to $200 \%$ the parental lines; Fu et al. 1990, Jain et al. 1994). Vegetables such as cabbage (B. oleracea) also exhibit high heterosis (Tanaka and Niikura 2006). Thus, $F_{1}$ hybrid breeding is useful for all Brassicaceae crops.

To enable $F_{1}$ hybrid breeding, an efficient, reliable and stable method of $F_{1}$ seed production without contamination by self-fertilized seeds from each parent is vital. Because of the size and structure of Brassicaceae flowers, it is impossible to implement commercial hybrid seed production based on manual emasculation and pollination, as practiced with Cucurbitaceae crops. The self-incompatibility system, reviewed by Kitashiba and Nasrallah (2014) in this issue, was developed mainly by Japanese breeders and has been effective in $F_{1}$ breeding of vegetable Brassicaceae. However, self-incompatibility is not always stable, and may be suppressed by high temperature or drought. Furthermore, amphidiploid species B. napus and B. juncea, which are the major oil seed crops, do not express self-incompatibility.

Communicated by T. Nishio

Received September 27, 2013. Accepted December 5, 2013.

*Corresponding author (e-mail: hiyamagi@cc.kyoto-su.ac.jp)
Cytoplasmic male sterility (CMS) is another trait applicable to $F_{1}$ seed production, which is stable and applicable to all Brassicaceae crops. CMS is a maternally inherited trait encoded by a gene located in the mitochondria. In CMS plants, pollen production is disturbed, whereas the function of the female organ is not generally affected. Expression of a mitochondrial CMS gene can be masked by nuclear fertility restorer $(R f)$ genes, allowing the plant to produce functional pollen. A combination of a nuclear genome that lacks $R f$ genes and a CMS-inducing mitochondrial genome leads to nuclear-cytoplasmic incompatibility and the CMS phenotype. CMS has been reported in a large number of plant species, and is very important both from practical breeding and from the fundamental genetic and evolutionary viewpoints. CMS has been covered in several excellent reviews (Budar and Berthomé 2007, Chase 2007, Delourme and Budar 1999, Gabay-Laughnan and Newton 2012, Prakash et al. 2009).

In this article, we focus on CMS in Brassicaceae crops, including the latest information in this field. First, we review the history of studies on Ogura CMS. Among CMS types of Brassicaceae, the CMS discovered by Ogura (1968), which is now popularly refered to by his name, has been studied most extensively and is used worldwide in $F_{1}$ breeding of B. napus, B. juncea, B. oleracea and $R$. sativus. Then, we describe other CMS types and their causal genes. Finally, we discuss the studies on $R f$ genes, which are found in the nuclear genome and suppress CMS. We also consider the effects of alien cytoplasm on general crop performance. 


\section{History of research on Ogura CMS}

Originally described in radish, Ogura CMS (Fig. 1) is also widely used in B. oleracea, B. juncea and B. napus. Ogura CMS is one of a few CMSs that have been studied in detail in terms of both their basic molecular mechanism and their practical use in breeding. The history of research on this CMS system reflects the development of breeding science in the last 50 years (Fig. 2).

Ogura CMS was discovered in Japanese radish (R. sativus) of an unknown cultivar (Ogura 1968). Although not well utilized in radish breeding in Japan, this CMS was introduced into European radish. Some European radishes have an $R f$ gene (Bannerot et al. 1977, Bonnet 1977), whereas Ogura (1968) observed that Japanese cultivars have no such gene. European scientists introduced Ogura CMS into B. napus by intergeneric hybridization and repeated back-crossing (Bannerot et al. 1974, Heyn 1976). The resultant alloplasmic lines of B. napus showed male sterility, but all of them had chlorotic leaves, yellowing at low temperatures (below $15^{\circ} \mathrm{C}$ ) (Pelletier et al. 1983). This chlorophyll deficiency, undesirable for breeders, was suggested to result from functional incompatibility between the $B$. napus nucleus and $R$. sativus chloroplasts.

To overcome chlorosis in Ogura CMS B. napus, cells of an alloplasmic male sterile $B$. napus line and a normal B. napus variety were fused (Jarl and Bornman 1988, Menczel et al. 1987, Pelletier et al. 1983), and regenerated plants without chlorophyll deficiency but retaining the male sterility were selected. In these lines, the alloplasmic chloroplasts derived from $R$. sativus were substituted with those from B. napus, and the plants grew normally even at low temperature. A CMS line was thus established and used in $B$. napus hybrid breeding. A similar cell fusion approach was also applied in B. juncea (Kirti et al. 1993, 1995a).

Cell fusion led to recombinations of Ogura CMS and

\section{Genetic research}

O Discovery of Ogura CMS in radish (Ogura 1968)

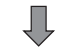

O Introduction of the CMS gene by intergeneric hybridization into Brassica (Bannerot et al. 1974)

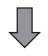

○ Use of cell fusion for chloroplast substitution (Pelletier et al. 1983)

』

O Molecular cloning:

- CMS gene: orf138 (Bonhomme et al. 1991)

- $R f$ gene: $\quad$ orf687 (Koizuka et al. 2003)

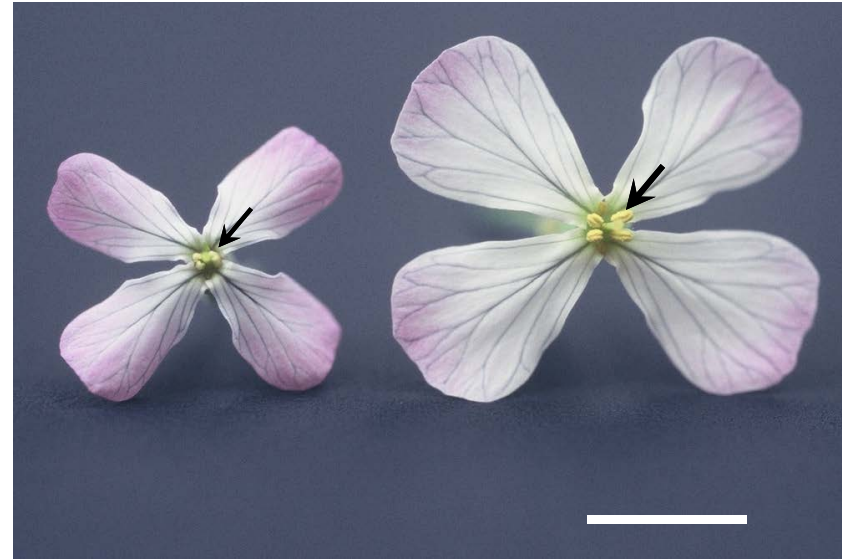

Fig. 1. Ogura cytoplasmic male sterile (left) and fertile (right) flowers found in a population of Japanese wild radish. Arrows show male sterile (left) and fertile (right) anthers. Scale bar $=1 \mathrm{~cm}$

B. napus mitochondrial genomes, and detailed analysis of the recombined mitochondrial genomes in these male sterile B. napus lines identified the causal gene of Ogura CMS (orf138) located upstream of orfB (Bonhomme et al. 1991, 1992, Grelon et al. 1994), now known as atp8 (Heazlewood et al. 2003). Orfl 38 was co-transcribed with $\operatorname{atp} 8$ (orfB) in male sterile plants. At least nine nucleotide sequence variants, including one with a deletion of 39 nucleotides (Kosena type), have been reported for orf138 (Yamagishi and Terachi 2001). Interestingly, nuclear expression of orf138 and targeting of ORF138 protein to mitochondria failed to induce male sterility in Arabidopsis thaliana, although ORF 138 expression led to an alteration in mitochondria in both plant and yeast cells (Duroc et al. 2006). Orf138 is widely distributed in Japanese wild radishes and another wild species of the same genus, e.g., $R$. raphanistrum, whereas most cultivated radishes have normal cytoplasm (Yamagishi and

\section{Breeding}

$\Rightarrow$ Use of CMS for $\mathrm{F}_{1}$ breeding in European radish

$\Rightarrow$ Establishment of alloplasmic CMS lines in Brassica $\Rightarrow \begin{aligned} & \text { Marker-assisted selection of } \\ & \text { the genes }\end{aligned}$

Fig. 2. History of genetic and breeding research on Ogura cytoplasmic male sterility. 
Terachi 1994, 1996, 1997), indicating that Ogura CMS originated in a wild Raphanus species and then spread in Japanese wild radishes. In progenies of spontaneous hybridization between the wild and cultivated radish, the male sterility was expressed and discovered by Ogura. Ogura (1968) described that the male sterile plants were of an unknown variety of Japanese radish which were growing under an escaped condition. This suggests hybridization between a wild radish as a female parent and a cultivated one as a pollen parent.

Some radish lines, including European varieties possess an $R f$ gene for Ogura CMS (Yamagishi 1998), whereas none of Brassica species has it. An $R f$ gene is essential for $\mathrm{F}_{1}$ hybrids of oil seed crops produced through the CMS system to set seeds properly. Therefore, the $R f$ gene $(R f k l)$ was introduced into Brassica from $R$. sativus cv. Kosena by protoplast fusion (Sakai et al. 1996). Rfkl was later cloned independently and almost simultaneously by three groups (Brown et al. 2003, Desloire et al. 2003, Koizuka et al. 2003), whereas Bett and Lydiate (2004) suggested the presence of three $R f$ genes in radish. The cloned $R f$ gene encodes a member of the pentatricopeptide repeat (PPR) family.

\section{Origins of CMS and male sterility-inducing mitochon- drial genes}

CMS is expressed phenotypically when CMS-inducing mitochondrial genome is combined with a nuclear genome that lacks $R f$ genes. Such combinations can arise de novo by spontaneous mutation in the mitochondrial genome, outcrossing within a species, or artificial hybridization. The latter includes sexual interspecific or intergeneric crosses, and somatic cell fusions. Here, Brassicaceae CMS types are described according to their origins; (1) intraspecific variations, (2) alloplasmic origin by interspecific or intergeneric hybridizations, and (3) cell fusion.

\section{(1) CMS caused by intraspecific variations}

Polima ( $p o l)$ CMS of B. napus is another well-known example of spontaneous male sterility (Fu 1981, Liu et al. 1987). As pol CMS is temperature-sensitive, its practical use in $\mathrm{F}_{1}$ hybrid breeding is limited, but the molecular basis of this CMS has been well studied. The mitochondrial genome of pol CMS plants contains orf224, a chimeric gene located upstream of and co-transcribed with the atp 6 gene. In the presence of $R f$ gene, processing of orf224/atp6 RNA is affected and the transcripts are specifically altered, suggesting that orf224 is the causal gene of pol CMS (L'Homme and Brown 1993, Singh and Brown 1993). Indeed, orf224 introduced into $B$. oleracea by somatic cell fusion induced male sterility (Wang et al. 1995). The structure of the protein encoded by orf222, which is responsible for nap CMS (another example of a natural mitochondrial variant within B. napus), is similar to that of the protein product of orf224 (L'Homme et al. 1997), although B. napus varieties in which male sterility is induced and the position of orf222 in the mitochondrial genome are different from orf224 (L'Homme et al. 1997).

Other spontaneous CMS variants include 681A in B. napus originated from cv. Xiangyu (Liu et al. 2005) and hau in B. juncea (Wan et al. 2008). Maintainer and restorer lines of 681A CMS are the same as those for pol, but $681 \mathrm{~A}$ lines differ from pol lines in their mitochondrial genome organization, suggesting that $681 \mathrm{~A}$ might be a variant of $\mathrm{pol}$ CMS. On the other hand, restorers for hau cytoplasm have not been identified so far and pol or nap restorers fail to rescue hau-induced male sterility (Wan et al. 2008).

Another novel CMS gene, orf288, co-transcribed with atp6 was discovered in hau CMS (Jing et al. 2012). Orf288 was cytotoxic to $E$. coli and induced male sterility in A. thaliana when expressed from the nuclear genome with or without the mitochondrial targeting presequences (Jing et al. 2012). It was further shown that ORF288 protein was targeted to the mitochondria even when not fused with mitochondrial targeting presequence. These results indicate that orf 288 might be the causal gene of hau CMS.

Recent studies on $R$. sativus discovered types of CMS other than Ogura CMS. One was found in Korean radish collections and named NWB CMS (Nahm et al. 2005); the $R f$ genes for this CMS have not yet been found. Another one was found in a radish of Uzbekistan (Kim et al. 2007, Lee et al. 2008, 2009). A study of the complete mitochondrial genome sequence of this CMS type, designated as DCGMS, identified the causal gene as a novel chimeric gene, orf463, consisting of a 128-bp partial sequences of coxI and a 1261bp sequence of unclear origin (Park et al. 2013).

Gobron et al. (2013) hybridized two distantly related accessions of $A$. thaliana and obtained male sterile strains whose inheritance pattern in reciprocal crosses suggested CMS. Mitochondrial genome analyses of the two accessions revealed that the causal gene of this CMS was orf117. The predicted ORF117 peptide is 56\% identical and 69\% similar to the ORF108 peptide from Moricandia arvensis that induces male sterility in B. juncea (see next section).

(2) Alloplasmic CMS as a result of interspecific or intergeneric hybridizations

Since the establishment of the CMS line of $B$. rapa with the cytoplasm of Diplotaxis muralis (Hinata and Konno 1979), several more male sterile lines have been developed in Brassicaceae (Table 1). In B. juncea, the most important oil seed crop in Southern Asia, the cytoplasms of at least eight species induce CMS (Banga et al. 2003, Kumar et al. 2012, Landgren et al. 1996, Malik et al. 1999, Pathania et al. 2003, Prakash and Chopra 1990, Prakash et al. 2001, Rao et al. 1994). In addition to D. muralis, four other cytoplasms induce CMS in B. rapa (Deol et al. 2003, Matsuzawa et al. 1999, Prakash and Chopra 1988, 1990, Tsutsui et al. 2011). Seven B. napus CMS lines are known, including the three (Ogura, pol and nap) mentioned above. The cytoplasm of D. muralis induces sterility also in B. oleracea (Shinada et al. 2006). Erucastrum canariense and M. arvensis 
Table 1. Combinations of nucleus and cytoplasm in alloplasmic CMS plants

\begin{tabular}{|c|c|}
\hline Source of the nucleus & Source of the cytoplasm \\
\hline Brassica rapa & $\begin{array}{l}\text { B. oxyrrhina }{ }^{a}, \text { Diplotaxis }_{\text {muralis }}^{a} \text {, } \\
\text { Enarthrocarpus lyratus }^{a}, \text { Eruca sativa, } \\
\text { Moricandia arvensis }^{a b}\end{array}$ \\
\hline B. oleracea & $\begin{array}{l}\text { D. } \text { muralis }^{a}, \text { Erucastrum canariense }^{a} \text {, } \\
\text { M. } \text { arvensis }^{a b}\end{array}$ \\
\hline B. juncea & 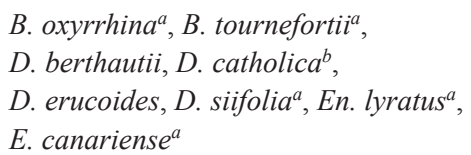 \\
\hline B. napus & $\begin{array}{l}\text { B. tournefortiia }{ }^{a b}, \text { D. } \text { muralis }^{a} \text {, } \\
\text { D. siifolia }{ }^{a}, \text { En. lyratus }^{a}\end{array}$ \\
\hline Raphanus sativus & B. maurorum \\
\hline
\end{tabular}

${ }^{a}$ Confers CMS in more than one species of Brassicaceae.

${ }^{b}$ Also used to produce CMS plants by cell fusion (see Table 2).

cytoplasms were recently reported to confer CMS in B. oleracea (Chamola et al. 2013a). A CMS line of $R$. sativus with the cytoplasm of B. maurorum was produced (Bang et al. 2011). As shown in Table 1, five species, B. oxyrrhina, B. tournefortii, D. muralis, D. siifolia and Enarthrocarpus lyratus, are effective as donors of male sterile cytoplasm for more than one crop species. The cytoplasm of $D$. muralis induces male sterility in B. rapa, $B$. oleracea and $B$. napus, whereas En. lyratus cytoplasm confers CMS in B. rapa, B. juncea and B. napus. CMS was also obtained in $B$. juncea as a result of interspecific hybridization between $B$. rapa and $B$. juncea; this CMS was later transferred to leaf mustard (B. juncea var. multiceps) (Yang et al. 2005), tuber mustard (B. juncea var. tumida) (Zhang et al. 2003) and stem mustard (B. juncea) (Yang et al. 2009). Male sterility in $B$. juncea CMS line was found to be associated with a novel gene, orf220, which shares 79 homology with orf222 (nap) and $81 \%$ with orf 224 (pol) of B. napus (Yang et al. 2005).

Three cytoplasms (D. berthautii, D. catholica and $D$. erucoides) that confer CMS to $B$. juncea commonly possess orf108 upstream of atp $A$, and the two genes are cotranscribed. Expression analyses suggested orf108 as the causal gene in these CMS sources (Kumar et al. 2012). Orf108 was also found in male sterile $B$. juncea obtained by cell fusion between $B$. juncea and $M$. arvensis. The CMS $B$. juncea line derived from the somatic hybridization with $M$. arvensis carried the unaltered mitochondrial genome from M. arvensis in which orf108 is present (Prakash et al. 1998). The finding is the first demonstration of a common molecular mechanism underlying CMS in lines of different origin (Ashutosh et al. 2008, Kumar et al. 2012). Apart from the above species, orf 108 was also found in other wild species including B. oxyrrhina, Sinapis alba, En. lyratus and $D$. tenuisilque, which suggests its wide distribution. However, orf108 was absent in D. muralis, D. siifolia and $D$. cretasia. Therefore, it appears that orf108 is of ancestral origin but is lost or modified in some lineages. Recent
Table 2. Combinations used to produce CMS plants by cell fusion

\begin{tabular}{|c|c|}
\hline Recipient & Cytoplasm donor \\
\hline Brassica rapa & Raphanus sativus $^{a}$ \\
\hline B. oleracea & Arabidopsis thaliana \\
\hline B. juncea & $\begin{array}{l}\text { Diplotaxis catholica }{ }^{a}, \text { Moricandia arvensis }^{a} \text {, } \\
\text { Trachystoma ballii }\end{array}$ \\
\hline B. napus & $\begin{array}{l}\text { A. thaliana, B. tournefortii }{ }^{a} \text {, } \\
\text { Orychophragmus violaceus, Sinapis arvensis }\end{array}$ \\
\hline
\end{tabular}

${ }^{a}$ Also used to produce alloplasmic CMS plants by sexual hybridization (see Table 1 and the main text).

finding in $A$. thaliana of CMS-associated orf 117 with $69 \%$ homology to orf108 (Gobron et al. 2013) further supports this view. Orf 263 was inferred to be the causal gene in the CMS lines of B. napus and B. juncea with the cytoplasm of B. tournefortii (Landgren et al. 1996). In the mitochondria of D. muralis, which induces CMS in three Brassica species (Table 1), a novel chimeric gene, orf72, located downstream of $r p s 7$ and containing a fragment of atp 9 , was identified. Comparison of gene expression and pollen fertility demonstrated the association of the orf 72 with CMS (Shinada et al. 2006).

\section{(3) CMS plants obtained by cell fusion}

In contrast to sexual hybridization, cell fusion does not require fertilization, and thus a much wider range of hybridization species can be used. Wild species not used in interspecific and intergeneric sexual hybridization have been used for cell fusion to produce male sterile lines (Table 2). In addition to $B$. tournefortii, $D$. catholica, $M$. arvensis and $R$. sativus, which have been used as cytoplasm donors in sexual hybridization, A. thaliana, Orychophragmus violaceus, Sinapis arvensis and Trachystoma ballii cytoplasms were transferred into $B$. napus, B. juncea or B. oleracea by somatic cell fusion to obtain CMS (Forsberg et al. 1994, 1998a, 1998b, Hu et al. 2004, Kirti et al. 1993, 1995a, 1995b, 1995c, Mei et al. 2003, Yamagishi et al. 2002, 2008, Yamagishi and Nakagawa 2004). Whereas alloplasmic CMS lines obtained by sexual hybridization inherit the mitochondrial genome of the female parent, somatic hybridization can give rise to novel recombined mitochondrial genomes derived from both parental species, which complicates identification of CMS causal genes. Hitherto, two genes have been identified that demonstrate contrasting features in relation to the CMS genes of alloplasmic lines.

The progeny of somatic hybrid between $B$. juncea and $M$. arvensis showing CMS had chloroplast and mitochondrial genomes identical to those of $M$. arvensis without recombination (Prakash et al. 1998). This CMS line had orf 108 upstream of atpA as the causal gene, similarly to alloplasmic plants obtained by sexual hybridization. The progeny of a somatic hybrid between $B$. napus and B. tournefortii (Stiewe and Röbbelen 1994) had orf193 upstream of atp9 (Dieterich et al. 2003), whereas in the 
alloplasmic lines of $B$. napus with the cytoplasm of B. tournefortii (as described in the previous section), orf 263 was the causal CMS gene. Thus, with the same parental combination, cell fusion and sexual hybridization resulted in different CMS genes, orf193 and orf263.

An improvement of a male-sterile line in B. juncea due to mitochondrial recombination has been reported. Plants with Ogura cytoplasm and B. juncea nucleus had flowers with petaloid anthers and poor female fertility. A fully female-fertile, anther-sterile CMS line was obtained through somatic hybridization (Kirti et al. 1995a).

A variation in the mitochondrial coxI-2 gene was suggested to cause CMS in a cell fusion between $B$. juncea and D. catholica (Pathania et al. 2007), although this has not been definitely proven. A recombined mitochondrial genome was found in B. napus CMS lines derived from somatic hybridization with $A$. thaliana (Carlsson et al. 2007, Leino et al. 2003, 2004, Teixeira et al. 2005). The association of fertility restoration with markers on chromosome 3 of $A$. thaliana suggested that the male sterility genes are also derived from $A$. thaliana (Leino et al. 2004).

CMS lines are characterized by comparing the mitochondrial genome organization and gene expression in male sterile, maintainer and fertility restored lines. The association of a mitochondrial gene with CMS is inferred when the gene is expressed only in the male sterile plant but is suppressed in the fertility restored plant carrying a nuclear $R f$ gene. Table 3 lists the CMS causal genes in Brassicaceae crops identified so far. Twelve genes have been cloned from ten species of original cytoplasm donors. Among the genes, eight have a chimeric structure consisting fragments of known mitochondrial gene and sequences of unknown origin.

\section{$\boldsymbol{R} f$ genes for the CMS}

When CMS system is applied for $F_{1}$ hybrid breeding of oil seed crops (B. juncea and B. napus), the $\mathrm{F}_{1}$ hybrid should be male fertile to ensure proper seed set. Therefore, the discovery of $R f$ genes capable of conferring male fertility to CMS plants is critical for exploiting CMS. $R f$ genes for intraspecific cytoplasmic variants are usually found among the germplasm lines of that species. For alloplasmic CMS lines derived from sexual or somatic hybridization, $R f$ genes are not generally found in the recipient species and need to be introgressed from species used as cytoplasm donors. $R f$ genes have been successfully transferred from other species into cultivated Brassica species for the CMS-inducing cytoplasms such as Ogura (Heyn 1976), T. ballii (Kirti et al. 1997), M. arvensis (Kirti et al. 1998), Er. canariense (Prakash et al. 2001), En. lyratus (Banga et al. 2003 ) and B. tournefortii (Janeja et al. 2003 ). Surprisingly, an $R f$ gene of $M$. arvensis restores fertility of three other cytoplasms, namely, D. catholica, D. erucoides and D. berthautii (Bhat et al. 2005, 2006, 2008). Fertility restoration in most Brassica CMS lines is sporophytic (i.e. $\mathrm{F}_{1}$ hybrid plants are $100 \%$ pollen-fertile). However, in CMS lines of $M$. arvensis, $D$. erucoides and D. berthautii, fertility restoration is gametophytic (Bhat et al. 2005), i.e., only $R f$ gene-carrying pollen is functional and thus $\mathrm{F}_{1}$ hybrid plants are $50 \%$ pollen-fertile (Fig. 3). Hence, the self progeny of gametophytically restored plants do not segregate for male sterility and fertility.

The relationships between mitochondrial CMS genes and their counterpart $R f$ genes are interesting from the point of view of studying co-evolution of mitochondrial and nuclear genomes. Such studies have been conducted for pol and nap CMS of B. napus, alloplasmic CMS lines of B. juncea and the Ogura CMS. As mentioned above, the proteins encoded by pol CMS and nap CMS genes have similar structure. The $R f$ genes for nap $(R f n)$ and pol $(R f p)$ are allelic (Li et al. 1998 ), and both affect mRNA processing of the CMS genes by inducing the removal of sequences from the $5^{\prime}$-ends of the transcripts (Brown 1999, Geddy et al. 2005, Menassa et al. 1999). $R f$ genes of different origin have a common function in alloplasmic B. juncea. As stated above, in B. juncea, four CMS lines have a common CMS gene (orf108, in Table 3), and share a common restorer gene. In the presence of the restorer, the bi-cistronic orf108-atpA transcript is cleaved just downstream of the start codon of orf108, leading to the production of monocistronic atp $A$ transcript

Table 3. CMS genes identified in the mitochondria of Brassicaceae crops

\begin{tabular}{|c|c|c|c|c|}
\hline Gene & $\begin{array}{l}\text { Normal gene } \\
\text { compounding orf }\end{array}$ & Adjacent gene & Origin & Recipient \\
\hline orf138 & None & atp 8 & R. sativus (Ogura) & R. sativus, Brassica species \\
\hline orf125 & None & atp 8 & R. sativus (Kosena) & R. sativus, Brassica species \\
\hline $\operatorname{orf} 224$ & atp 8, rps 3 & atp6 & B. napus (pol) & B. napus \\
\hline orf 222 & atp 8 & nad $5 c$, orf139 & B. napus (nap) & B. napus \\
\hline orf463 & $\operatorname{cox} I$ & None & R. sativus (DCGMS) & R. sativus \\
\hline orf117 & None & None & A. thaliana & A. thaliana \\
\hline $\operatorname{orf} 72$ & atp9 & $\operatorname{rsp} 7$ & D. muralis & B. oleracea \\
\hline orf108 & None & $\operatorname{atp} A$ & $\begin{array}{l}\text { D. erucoides, D. berthautii, D. catholica, } \\
\text { M. arvensis (by cell fusion) }\end{array}$ & B. juncea \\
\hline $\operatorname{orf} 263$ & nad5 & atp6 & B. tournefortii & B. napus, B. juncea \\
\hline orf193 & atp6 & apt9-2 & B. tournefortii (by cell fusion) & B. napus \\
\hline orf 220 & atp 8, rps 3 & atp $A$ & B. rapa & B. juncea \\
\hline $\operatorname{orf} 288$ & nad5 & atp6 & B. rapa & B. juncea \\
\hline
\end{tabular}




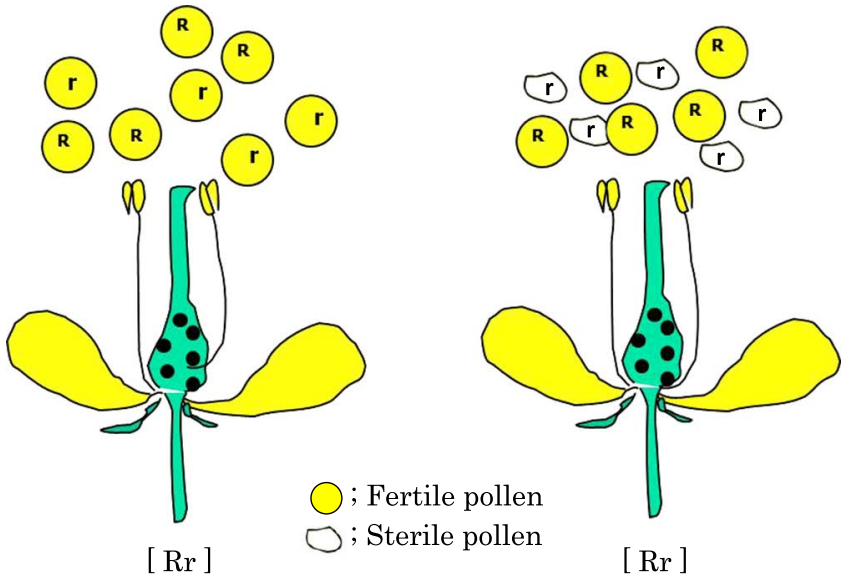

Fig. 3. Sporophytic (left) and gametophytic (right) modes of pollen fertility restoration. R; Functional restorer allele, r; Non-functional restorer allele.

(Ashutosh et al. 2008, Kumar et al. 2012). These findings are noteworthy, as they indicate that the common genetic mechanisms of CMS and fertility restoration have evolved and are shared by different species and genera.

For Ogura CMS, the $R f$ gene, orf687 (Brown et al. 2003, Desloire et al. 2003, Koizuka et al. 2003), does not affect transcription of the orf138, but regulates orf138 mRNA translation. In Japanese wild radishes, where $R f$ genes for Ogura CMS are common, the frequency of plants with orf687 is small (Yasumoto et al. 2008). Another $R f$ gene $(R f t)$, found in most Japanese wild radishes, regulates orf138 mRNA processing (Yasumoto et al. 2009). This finding indicates that $R f$ genes with different molecular mechanisms have evolved in radish to suppress the expression of orf138, the causal gene of Ogura CMS.

\section{Cytoplasmic effects, retrograde regulation and poly- morphic floral phenotypes}

Availability of alien CMS systems in Brassicaceae crops raises the question of adverse effects associated with alien cytoplasm, as deployment of CMS for commercial hybrid development would require absence of any such effects, which could be due to plastid or mitochondrial genomes. The negative effect of incompatible plastids causing leaf chlorosis in CMS B. rapa, B. juncea or B. napus lines with Ogura, $B$. oxyrrhina, $M$. arvensis cytoplasm, and chloroplast substitution as an approach to overcome this problem, have already been discussed above (Kirti et al. 1993, 1995a). CMS lines of $B$. juncea carrying Ogura, D. catholica or T. ballii cytoplasm show poor female fertility (Chamola et al. 2013b, Pathania et al. 2003). In most cases, only those mitochondrial genes that are directly associated with male sterility have been studied. Although the expression patterns of many other mitochondrial genes are also altered in the CMS lines, the effects of such changes and the role of $R f$ genes in correcting other defects have rarely been investi- gated. Recently, Chamola et al. (2013b) compared in detail the effects of alien cytoplasms in $B$. juncea. In the T. balli-based CMS system, a restorer gene could completely reverse the negative effect of cytoplasm on seed yield and yield-contributing traits, whereas in $D$. catholica-based CMS, a restorer gene was only partially effective. Another effect that could come into play in alien CMS systems is the linkage drag associated with the introgressed $R f$ gene. Introgression of a restorer gene for Ogura CMS from $R$. sativus into $B$. napus brought along an unwanted gene responsible for seed glucosinolate synthesis, and it took considerable effort and time to break this linkage (Delourme et al. 1995, Primard-Brisset et al. 2005).

Although CMS has been attributed to specific mitochondrial genes, diverse floral phenotypes induced by the same cytoplasm in different species have not been fully investigated. For example, although orf108 causes CMS in $B$. juncea lines carrying $D$. catholica, D. berthautii, $D$. erucoides or $M$. arvensis mitochondria, and all these CMS lines are restored by a common restorer (Bhat et al. 2005, 2006, 2008), D. catholica cytoplasm leads to a petaloid anther, multilocular silique, and poor female fertility whereas others result only in gametophytic pollen sterility. Ogura cytoplasm leads to petaloid anthers in $B$. juncea but sterile anthers in B. napus. The fact that the same fertility restorer gene from $R$. sativus restores male fertility in CMS lines of B. napus and B. juncea carrying Ogura cytoplasm indicates that orf 138 causes male sterility in both the cases. Therefore, how orf138 expression in B. juncea leads to petaloid anther remains unresolved. Yang et al. (2008) have shown that CMS phenotypes could be partially mimicked by treating plants with chemical inhibitors of mitochondrial electron transport. Therefore, polymorphic phenotypes are likely to result from differences in the energy status of cells due to expression of CMS-inducing mitochondrial genes in different nuclear backgrounds. For instance, B. napus CMS lines carrying a recombined $A$. thaliana mitochondrial genome exhibited altered sugar metabolism (Teixeira et al. $2005)$ and showed retrograde regulation of floral homeotic genes $A P 3$ and $P I$ (Carlsson et al. 2007). Similar retrograde regulation of $A P 3, P I$ and $A G$ was also reported in CMS lines of stem mustard displaying petaloid anthers (Yang et al. 2008). Retrograde regulation of BjRCE1 gene in CMS $B$. juncea led to altered auxin response (Yang et al. 2012) which would in turn affect multiple traits. Differences in miRNA expression between CMS and maintainer lines of $B$. juncea also indicate that retrograde regulation leads to various changes (Yang et al. 2013). Recently, Dong et al. (2013) compared the floral transcriptomes of Ogura CMS Chinese cabbage (B. rapa ssp. pekinensis) and the maintainer line, and found more than 100 differentially expressed genes. Thus, traits besides male sterility could be affected in CMS lines, and future studies should focus on global transcriptome changes in male sterile and fertility restored lines to assess the effects of CMS on agronomic performance.

Although novel mitochondrial orfs causing male sterility 
have been discovered, their precise mode of evolution and significance beyond male sterility has not been critically examined. For example, in corn, the Texas CMS also makes plants susceptible to Southern corn leaf blight pathogen Cochliobolus heterostrophus (Miller and Koeppe 1971) and this adverse effect is not rectified by the restorer gene. Likewise, molecular details of processing of CMS-associated transcripts or proteins by the nuclear $R f$ genes remain to be elucidated in the Brasicaceae crops.

Studies discussed above suggest that CMS in lines of different origin may have common molecular mechanisms. A similar resemblance may also be found among $R f$ genes. On the other hand, multiple ways of fertility restoration through evolution of different $R f$ genes (as in the case of Ogura CMS) are also evident. Further detailed and integrated studies are expected to clarify the evolutionary relationships of CMS and $R f$ genes. Such studies would also contribute to establishing efficient $F_{1}$ hybrid breeding systems in Brasicaceae crops.

\section{Acknowledgement}

We would like to thank Dr. K. Yasumoto for his useful advice.

\section{Literature Cited}

Ashutosh, P.Kumar, P.C. Sharma, S.Prakash and S.R. Bhat (2008) A novel orf108 co-transcribed with atpA gene is associated with cytoplasm male sterility in Brassica juncea carrying Moricandia arvensis cytoplasm. Plant Cell Physiol. 49: 284-289.

Bang, S.W., K. Tsutsui, S. Shim and Y.Kaneko (2011) Production and characterization of the novel CMS line of radish (Raphanus sativus) carrying Brassica maurorum cytoplasm. Plant Breed. 130: 410-412.

Banga, S.S., J.S. Deol and S.K. Banga (2003) Alloplasmic male-sterile Brassica juncea with Enarthrocarpus lyratus cytoplasm and the introgression of gene(s) for fertility restoration from cytoplasm donor species. Theor. Appl. Genet. 106: 1390-1395.

Bannerot, H., L. Boulidard, Y. Cauderon and J. Temp (1974) Transfer of cytoplasmic male sterility from Raphanus sativus to Brassica oleracea. Eucarpia Meeting Cruciferae, Dundee, Scotland, pp. 5254.

Bannerot, H., L. Boulidard and Y.Cauderon (1977) Unexpected difficulties met with the radish cytoplasm. Eucarpia Cruciferae Newsletter 2: 16.

Bett, K.E. and D.J.Lydiate (2004) Mapping and genetic characterization of loci controlling the restoration of male fertility in Ogura CMS radish. Mol. Breed. 13: 125-133.

Bhat, S.R., S.Prakash, P.B.Kirti, V.Dineshkumar and V.L.Chopra (2005) A unique introgression from Moricandia arvensis confers male fertility upon two different cytoplasmic male-sterile lines of Brassica juncea. Plant Breed. 124: 117-120.

Bhat, S.R., V.Priya, Ashutosh, K.K.Dwivedi and S.Prakash (2006) Diplotaxis erucoides induced cytoplasmic male sterility in Brassica juncea is rescued by the Moricandia arvensis restorer: genetic and molecular analyses. Plant Breed. 125: 150-155.
Bhat, S.R., P. Kumar and S. Prakash (2008) Am improved cytoplasmic male sterile (Diplotaxis berthautii) Brassica juncea: identification of restorer and molecular characterization. Euphytica 159: 145152.

Bonhomme, S., F. Budar, M. Férault and G.Pelletier (1991) A 2.5 kb $\mathrm{NcoI}$ fragment of Ogura radish mitochondrial DNA is correlated with cytoplasmic male-sterility in Brassica cybrids. Curr. Genet. 19: 121-127.

Bonhomme, S., F. Budar, D.Lancelin, I.Small, M.C.Defrance and G. Pelletier (1992) Sequence and transcript analysis of the Nco2.5 Ogura-specific fragment correlated with cytoplasmic male sterility in Brassica cybrids. Mol. Gen. Genet. 235: 340-348.

Bonnet, A. (1977) Breeding in France of a radish $F_{1}$ hybrid obtained by use of cytoplasmic male sterility. Eucarpia Cruciferae Newsletter 2: 5 .

Brown, G.G. (1999) Unique aspects of cytoplasmic male sterility and fertility restoration in Brassica napus. J. Heredity 90: 351-356.

Brown, G.G., N. Formanová, H. Jin, R. Wargachuk, C. Dendy, P. Patil, M.Laforest, J.Zhang, W.Y. Cheung and B.S.Landry (2003) The radish $R f o$ restorer gene of Ogura cytoplasmic male sterility encodes a protein with multiple pentatricopeptide repeats. Plant J. 35: 262-272.

Budar,F. and R.Berthomé (2007) Cytoplasmic male sterilities and mitochondrial gene mutations in plants. In: Plant mitochondria: annual plant reviews. Vol. 31. Edited by D.C. Logan. Blackwell Publishing Ltd., Oxford, UK, pp. 278-307.

Carlsson, J., U.Lagercrantz, J. Sundström, R. Teixeira, F. Wellmer, E.M.Meyerowitz and K.Glimelius (2007) Microarray analysis reveals altered expression of a large number of nuclear genes in developing cytoplasmic male sterile Brassica napus flowers. Plant J. 49: 452-462.

Chamola, R., H.S. Balyan and S.R. Bhat (2013a) Transfer of cytoplasmic male sterility from alloplasmic Brassica juncea and B. napus to cauliflower ( $B$. oleracea var. botrytis) through interspecific hybridization and embryo culture. Ind. J. Genet. 73: 203-210.

Chamola, R., H.S. Balyan and S.R. Bhat (2013b) Effect of alien cytoplasm and fertility restorer genes on agronomic and physiological traits of Brassica juncea (L.) Czern. Plant Breed. 132: 681-687.

Chase, C.D. (2007) Cytoplasmic male sterility: a window to the world of plant mitochondrial-nuclear interactions. Trans. Genet. 23: 8190 .

Delourme, R., F.Eber and M.Renard (1995) Breeding double low restorer lines in radish cytoplasmic male sterility of rapeseed (Brassica napus L.). In: Proc. 9th Int. Rapeseed Cong., Vol. 1. Cambridge, UK, pp. 6-8.

Delourme, R. and F. Budar (1999) Male Sterility. In: Gómez-Campo, C. (ed.) Biology of Brassica coenospecies, Elsevier Science, Amsterdam, pp. 185-216.

Deol, J.S., K.R. Shivanna, S.Prakash and S.S.Banga (2003) Enarthrocarpus lyratus-based cytoplasmic male sterility and fertility restorer system in Brassica rapa. Plant Breed. 122: 438-440.

Desloire, S., H. Gherbi, W. Laloui, S. Marhadour, V.Clouet, L. Cattolico, C. Falentin, S. Giancola, M. Renard, F.Budar et al. (2003) Identification of the fertility restoration locus, Rfo, in radish, as a member of the pentatricopeptiderepeat protein family. EMBO Rep. 4: 588-594.

Dieterich, J.H., H.P. Braun and U.K. Schmitz (2003) Alloplasmic male sterility in Brassica napus (CMS 'Tournefortii-Stiewe') is associated with a special gene arrangement around a novel atp 9 gene. Mol. Genet. Genomics. 269: 723-731.

Dong, X., W.K.Kim, Y.P.Lim, Y.K.Kim and Y.Hur (2013) Ogura- 
CMS in Chinese cabbage (Brassica rapa ssp. pekinensis) causes delayed expression of many nuclear genes. Plant Sci. 199-200: 7-17.

Duroc, Y., C. Gaillard, S. Hiard, C.Tinchant, R. Berthom, G. Pelletier and F. Budar (2006) Nuclear expression of a cytoplasmic male sterility gene modifies mitochondrial morphology in yeast and plant cells. Plant Sci. 170: 755-767.

Forsberg, J., M. Landgren and K. Glimelius (1994) Fertile somatic hybrids between Brassica napus and Arabidopsis thaliana. Plant Sci. 95: 213-223.

Forsberg, J., C. Dixelius, U. Lagercrantz and K. Glimelius (1998a) UVdose dependent DNA elimination in asymmetric somatic hybrids between Brassica napus and Arabidopsis thaliana. Plant Sci. 137: 65-76.

Forsberg, J., U.Lagercrantz and K. Glimelius (1998b) Comparison of UV-light, X-ray and restriction enzyme treatment as tools in production of asymmetric somatic hybrids between Brassica napus and Arabidopsis thaliana. Theor. Appl. Genet. 96: 1178-1185.

Fu, T.D. (1981) Production and research on rapeseed in the Peoples Republic in China. Cruciferae Newsl. 6: 6-7.

Fu, T., G. Yang and X. Yang (1990) Studies on "three line" Polima cytoplasmic male sterility developed in Brassica napus. Plant Breed. 104: 115-120.

Gabay-Laughnan, S. and K.J.Newton (2012) Plant mitochondrial mutations. In: Bock, R. and V.Knoop (eds.) Genomics of Chloroplast and Mitochondria. Springer, pp. 267-291.

Geddy, R., L. Mahé and G.G. Brown (2005) Cell-specific regulation of a Brassica napus CMS-associated gene by a nuclear restorer with related effects on a floral homeotic gene promoter. Plant J. 41: 333-345.

Gobron, N., C. Waszczak, M.Simon, S. Hiard, S. Boivin, D. Charif, A.Ducamp, E. Wenes and F. Budar (2013) A criptic cytoplasmic male sterility unveils a possible gynodioecious past for Arabidopsis thaliana. PLoS One 8: 1-13.

Grelon, M., F. Budar, S. Bonhomme and G. Pelletier (1994) Ogura cytoplasmic male-sterility (CMS)-associated $\operatorname{orf138}$ is translated into a mitochondrial membrane polypeptide in male sterile Brassica cybrids. Mol. Gen. Genet. 243: 540-547.

Heazlewood, J.L., J. Whelan and A.H.Millar (2003) The products of mitochondrial orf 25 and $\operatorname{orf} B$ genes are $\mathrm{F} 0$ components in the plant F1F0 ATP synthase. FEBS Lett. 540: 201-205.

Heyn,F.W. (1976) Transfer of restorer genes from Raphanus to cytoplasmic male sterile Brassica napus. Cruciferae Newslett. 1: 1516.

Hinata, K. and N. Konno (1979) Studies on a male-sterile strain having the Brassica campestris nucleus and the Diplotaxis muralis cytoplasm. Jpn. J. Breed. 29: 305-311.

Hu, Q., Y.Li, D. Mei, X. Fang, L.N.Hansen and S.B.Andersen (2004) stablishment and identification of cytoplasmic male sterility in Brassica napus by intergeneric somatic hybridization. Scientia Agricultura Sinica 37: 333-338.

Jain,A., S.Bhatia, S.S.Banga, S.Prakash and M.Lakshmikumaran (1994) Potential use of random amplified polymorphic DNA (RAPD) to study the genetic diversity in Indian mustard (Brassica juncea (L) Czern and Coss) and its relationship with heterosis. Theor. Appl. Genet. 88: 116-122.

Janeja, H.S., S.S. Banga and M.Lakshmikumaran (2003) Identification of AFLP markers linked to fertility restorer genes for tournefortii cytoplasmic male-sterility system in Brassica napus. Theor. Appl. Genet. 107: 148-154.

Jarl, C.I. and C.H. Bornman (1988) Correction of chlorophyll-defective, male sterile winter oilseed rape (Brassica napus) through organelle exchange: phenotypic evaluation of progeny. Hereditas 108: 97102.

Jing, B., S. Heng, D. Tong, Z. Wan, T. Fu, J. Tu, C. Ma, B. Yi, J. Wen and J.Shen (2012) A male sterility-associated cytotoxic protein ORF288 in Brassica juncea causes aborted pollen development. J. Exp. Bot. 63: 1285-1295.

Kim, S., H.Lim, S. Park, K. Cho, S. Sung, D. Oh and K. Kim (2007) Identification of a novel mitochondrial genome type and development of molecular makers for cytoplasm classification in radish (Raphanus sativus L.). Theor. Appl. Genet. 115: 1137-1145.

Kirti, P.B., S.B. Narasimhulu, T. Mohapatra, S. Prakash and V.L. Chopra (1993) Correction of chlorophyll deficiency in alloplasmic male sterile Brassica juncea through recombination between chloroplast genome. Genet. Res. Camb. 62: 11-14.

Kirti, P.B., S.S. Banga, S. Prakash and V.L. Chopra (1995a) Transfer of Ogu cytoplasmic male sterility to Brassica juncea and improvement of male sterile through somatic cell fusion. Theor. Appl. Genet. 91: 517-521.

Kirti, P.B., T. Mohapatra, S. Prakash and V.L. Chopra (1995b) Development of a stable cytoplasmic male sterile line of Brassica juncea from somatic hybrid Trachystoma ballii+Brassica juncea. Plant Breed. 114: 434-438.

Kirti,P.B., T. Mohapatra, H. Khanna, S.Prakash and V.L.Chopra (1995c) Diplotaxis catholica + Brassica juncea somatic hybrids: molecular and cytogeneric characterization. Plant Cell Rep. 14: 593-597.

Kirti,P.B., A.Baldev, K. Gaikwad, S.R.Bhat, V.Dineshkumar, S. Prakash and V.L. Chopra (1997) Introgression of a gene restoring fertility to CMS (Trachystoma) Brassica juncea and the genetics of restoration. Plant Breed. 116: 1179-1182.

Kirti, P.B., S.Prakash, K. Gaikwad, S.R.Bhat, V.Dineshkumar and V.L. Chopra (1998) Chloroplast substitution overcomes leaf chlorosis in a Moricandia arvensis -based cytoplasmic male sterile Brassica juncea. Theor. Appl. Genet. 97: 1179-1182.

Kitashiba,H. and J.B. Nasrallah (2014) Self-incompatibility in Brassicaceae crops: lessons for interspecific incompatibility. Breed. Sci. 64: 23-37.

Koizuka, N., R. Imai, H. Fujimoto, T. Hayakawa, Y. Kimura, J. KohnoMurase, T. Sakai, S. Kawasaki and J. Imamura (2003) Genetic characterization of a pentatricopeptide repeat protein gene, orf687, that restores fertility in the cytoplasmic male-sterile Kosena radish. Plant J. 34: 407-415.

Kumar, P., N. Vasupalli, R. Srinivasan and S.R. Bhat (2012) An evolutionarily conserved mitochondrial orf108 is associated with cytoplasmic male sterility in different alloplasmic lines of Brassica juncea and induces male sterility in transgenic Arabidopsis thaliana. J. Exp. Bot. 63: 2921-2932.

Landgren, M., M.Zetterstrand, E. Sundberg and K. Glimelius (1996) Alloplasmic male-sterile Brassica lines containing B. tournefortii mitochondria express an ORF $3^{\prime}$ of the atp6 gene and a $32 \mathrm{kDa}$ protein. Plant Mol. Biol. 32: 879-890.

Lee, Y., S. Park, C. Lim, H. Kim, H.Lim, Y.Ahn, S. Sung, M. Yoon and S. Kim (2008) Discovery of a novel cytoplasmic male-sterility and its restorer lines in radish (Raphanus sativus L.). Theor. Appl. Genet. 117: 905-913.

Lee, Y., S. Kim, H.Lim, Y.Ahn and S. Sung (2009) Identification of mitochondrial genome rearrangements unique to novel cytoplasmic male-sterility in radish (Raphanus sativus L.). Theor. Appl. Genet. 118: 719-728.

Leino, M., R. Teixeira, M. Landgren and K. Glimelius (2003) Brassica 
napus lines with rearranged Arabidopsis mitochondria display CMS and a range of developmental aberrations. Theor. Appl. Genet. 106: 1156-1163.

Leino, M., S. Thyselius, M.Landgren and K. Glimelius (2004) Arabidopsis thaliana chromosome III restores fertility in a cytoplasmic male-sterile Brassica napus line with A. thaliana mitochondrial DNA. Theor. Appl. Genet. 109: 272-279.

L'Homme, Y. and G.G. Brown (1993) Organizational differences between cytoplasmic male sterile and male fertile Brassica mitochondrial genomes are confined to a single transposed locus. Nucleic Acids Res. 21: 1903-1909.

L'Homme, Y., R.J. Stahl, X.Q. Li, A. Hameed and G.G. Brown (1997) Brassica nap cytoplasmic male sterility is associated with expression of a mtDNA region containing a chimeric gene similar to the pol CMS-associated orf224 gene. Curr. Genet. 31: 325-335.

Li, X.Q., M.Jean, B.S. Landry and G.G. Brown (1998) Restorer genes for different forms of Brassica cytoplasmic male sterility map to a single nuclear locus that modifies transcripts of several mitochondrial genes. Proc. Natl. Acad. Sci. USA 95: 10032-10037.

Liu, H., T.Fu and X. Yang (1987) Discovery and studies on Polima CMS line. Proc. 7th Int. Rapeseed Cong., 11-14 May 1987, Pozman, Poland: 69-78.

Liu,Z., C. Guan, F. Zhao and S. Chen (2005) Inheritance and mapping of a restorer gene for the rapeseed cytoplasmic male sterile line 681A. Plant Breed. 124: 5-8.

Malik, M., P. Vyas, N.S. Rangaswamy and K.R. Shivanna (1999) Development of two new cytoplasmic male sterile lines of Brassica juncea through wide hybridization. Plant Breed. 118: 75-78.

Matsuzawa,Y., S.Mekiyanon, Y.Kaneko, S.W.Bang, K. Wakui and Y. Takahata (1999) Male sterility in alloplasmic Brassica rapa L. carrying Eruca sativa cytoplasm. Plant Breed. 118: 82-84.

Mei,D., Y.Li and Q.Hu (2003) Study of male sterile line derived from intergeneric hybrids of Brassica napus + Orychophragmus violaceus and B. napus + Sinapis arvensis. Chinese J. Oil Crop Sci. 25: 72-75.

Menassa, R., Y.L'Homme and G.G. Brown (1999) Post-transcriptional and developmental regulation of a CMS-associated mitochondrial gene region by a nuclear restorer gene. Plant J. 17: 491-499.

Menczel,L., A. Morgan, S. Brown and P.Maliga (1987) Fusionmediated combination of Ogura-type cytoplasmic male sterility with Brassica napus plastids using X-irradiated CMS protoplasts. Plant Cell Rep. 6: 98-101.

Miller, R. and D. Koeppe (1971) Southern corn leaf blight: susceptible and resistant mitochondria. Science 173: 67-69.

Nahm, S.H., H.J.Lee, S.W.Lee, G.Y.Joo, C.H.Harm, S.G. Yang and B.W.Min (2005) Development of a molecular marker specific to a novel CMS line in radish (Raphanus sativus L.) Theor. Appl. Genet. 111: 1191-1200.

Ogura, H. (1968) Studies on the new male-sterility in Japanese radish, with special reference to the utilization of this sterility towards the practical raising of hybrid seeds. Mem. Fac. Agric. Kagoshima Univ. 6: 39-78.

Park, J.Y., Y. Lee, J. Lee, B. Choi, S. Kim and T. Yang (2013) Complete mitochondrial genome sequence and identification of a candidate gene responsible for cytoplasmic male sterility in radish (Raphanus sativus L.) containing DCGMS cytoplasm. Theor. Appl. Genet. 126: $1763-1774$.

Pathania,A., S.R.Bhat, V.DineshKumar, Asutosh, S.Prakash and V.L.Chopra (2003) Cytoplasmic male sterility in alloplasmic Brassica juncea carrying Diplotaxis catholica cytoplasm: molecular characterization and genetics of fertility restoration. Theor.
Appl. Genet. 107: 455-461.

Pathania,A., R.Kumar, V.Dinesh Kumar, Asutosh, K.K. Dwivedi, P.B. Kirti, S. Prakash, V.L. Chopra and S.R. Bhat (2007) A duplication of coxI gene is associated with CMS (Diplotaxis catholica) Brassica juncea derived from somatic hybridization with Diplotaxis catholica. J. Genet. 86: 93-101.

Pelletier, G., C. Primard, F. Vedel, P.Chétrit, R. Rémy, P. Rousselle and M.Renard (1983) Intergeneric cytoplasmic hybridization in Cruciferae by protoplast fusion. Mol. Gen. Genet. 191: 244-250.

Prakash, S. and V.L. Chopra (1988) Synthesis of alloplasmic Brassica campestris as a new source of cytoplasmic male sterility. Plant Breed. 101: 253.

Prakash, S. and V.L. Chopra (1990) Male sterility caused by cytoplasm of Brassica oxyrrhina in B. campestris and B. juncea. Theor. Appl. Genet. 79: 285-287.

Prakash, S., P.B.Kirti, S.R.Bhat, K. Gaikwad, V.D.Kumar and V.L. Chopra (1998) A Moricandia arvensis based cytoplasmic male sterility and fertility restoration system in Brassica juncea. Theor. Appl. Genet. 97: 488-492.

Prakash, S., I.Ahuja, H.C.Uprety, V.D. Kumar, S.R. Bhat, P.B. Kirti and V.L.Chopra (2001) Expression of male sterility in alloplasmic Brassica juncea with Erucastrum canariense cytoplasm and the development of a fertility restoration system. Plant Breed. 120: 479-482.

Prakash, S., S.R. Bhat and T. Fu (2009) Wild germplasm and male sterility. In: S. K. Gupta (ed.) Biology and breeding of crucifers, CRC Press, pp. 113-127.

Primard-Brisset, C., J.P.Poupard, R. Horvais, F.Eber, G.Pelletier, M. Renard and R. Delourme (2005) A new recombined double low restorer line for the Ogu-INRA CMS in rapeseed (Brassica napus L.). Theor. Appl. Genet. 111: 736-746.

Rao, G.U., V. Batra Sarup, S. Prakash and K.R. Shivanna (1994) Development of a new cytoplasmic male-sterility system in Brassica juncea through wide hybridization. Plant Breed. 112: 171-174.

Sakai, T., H.J.Liu, M.Iwabuchi, J.Kohno-Murase and J.Imamura (1996) Introduction of a gene from fertility restored radish (Raphanus sativus) into Brassica napus by fusion of $\mathrm{x}$-irradiated protoplasts from a radish restorer line and iodacetoamide-treated protoplasts from a cytoplasmic male-sterile cybrid of B. napus. Theor. Appl. Genet. 93: 373-379.

Shinada, T., Y.Kikucho, R. Fujimoto and S. Kishitani (2006) An alloplasmic male-sterile line of Brassica oleracea harboring the mitochondria from Diplotaxis muralis expresses a novel chimeric open reading frame, orf72. Plant Cell Physiol. 47: 549-553.

Singh, M. and G.G. Brown (1993) Characterization of expression of a mitochondrial gene region associated with the Brassica "Polima" CMS: developmental influences. Curr. Genet. 24: 316-322.

Stiewe, G. and G.Röbbelen (1994) Establishing cytoplasmic male sterility in Brassica napus by mitochondrial recombination with B. tournefortii. Plant Breed. 113: 294-304.

Tanaka, N. and S. Niikura (2006) Genetic analysis of the developmental characteristics related to the earliness of head formation in cabbage (Brassica oleracea L.). Breed. Sci. 56: 147-153.

Teixeira, R.T., I. Farbos and K. Glimelius (2005) Expression levels of meristem identity and homeotic genes are modified by nuclearmitochondrial interactions in alloplasmic male-sterile lines of Brassica napus. Plant J. 42: 731-742.

Tsutsui, K., B.H.Jeong, Y.Ito, S.W.Bang and Y.Kaneko (2011) Production and characterization of an alloplasmic and monosomic addition line of Brassica rapa carrying the cytoplasm and one chromosome of Moricandia arvensis. Breed. Sci. 61: 373-379. 
Wan, Z., B. Jing, J. Tu, C. Ma, J. Shen, B. Yi, J. Wen, T. Huang, X. Wnag and T.Fu (2008) Genetic characterization of a new cytoplasmic male sterility system (hau) in Brassica juncea and its transfer to B. napus. Theor. Appl. Genet. 116: 355-362.

Wang,H.M., T.Ketela, W.A. Keller, S.C.Gleddie and G.G.Brown (1995) Genetic correlation of the orf224/atp6 gene region with Polima CMS in Brassica somatic hybrids. Plant Mol. Biol. 27: 801-807.

Yamagishi,H. (1998) Distribution and allelism of restorer genes for Ogura cytoplasmic male sterility in wild and cultivated radishes. Genes \& Genetic Systems 73: 79-83.

Yamagishi,H. and T. Terachi (1994) Molecular and biological studies on male sterile cytoplasm in Cruciferae. II. The origin of Ogura male sterile cytoplasm inferred from the segregation pattern of male sterility in the $\mathrm{F}_{1}$ progeny of wild and cultivated radishes (Raphanus sativus L.). Euphytica 80: 201-206.

Yamagishi,H. and T. Terachi (1996) Molecular and biological studies on male sterile cytoplasm in the Cruciferae. III. Distribution of Ogura-type cytoplasm among Japanese wild radishes and Asian radish cultivars. Theor. Appl. Genet. 93: 325-332.

Yamagishi,H. and T. Terachi (1997) Molecular and biological studies on male sterile cytoplasm in the Cruciferae. IV. Ogura-type cytoplasm found in the wild radish, Raphanus raphanistrum. Plant Breed. 116: 323-329.

Yamagishi,H. and T. Terachi (2001) Intra- and inter-specific variations in the mitochondrial gene orf138 of Ogura-type male sterile cytoplasm from Raphanus sativus and Raphanus raphanistrum. Theor. Appl. Genet. 103: 725-732.

Yamagishi, H., M.Landgren, J. Forsberg and K. Glimelius (2002) Production of asymmetric hybrids between Arabidopsis thaliana and Brassica napus utilizing an efficient protoplast culture system. Theor. Appl. Genet. 104: 959-964.

Yamagishi,H. and S.Nakagawa (2004) Somatic hybrids between Arabidopsis thaliana and cabbage (Brassica oleracea). J. Jpn. Soc. Hort. Sci. 73: 319-323.

Yamagishi,H., S.Nakagawa, D. Kinoshita, A.Ishibashi and
Y. Yamashita (2008) Somatic hybrids between Arabidopsis thaliana and cabbage (Brassica oleracea L.) with all chromosomes derived from A. thaliana and low levels of fertile seed. J. Jpn. Soc. Hort. Sci. 77: 277-282.

Yang, J., X. Liu, B. Xu, N. Zhao, X. Yang and M.Zhang (2013) Identification of miRNAs and their targets using high-throughput sequencing and degradome analysis in cytoplasmic male-sterile and its maintainer fertile lines of Brassica juncea. BMC Genomics 14: 9.

Yang, J.H., M.F.Zhang, J.Q.Yu, S.Zhang, T.Wang and Z.J.Chen (2005) Identification of alloplasmic cytoplasmic male-sterile line of leaf mustard synthesized by intra-specific hybridization. Plant Sci. 168: 865-871.

Yang, J.H., X.H.Qi, M.F.Zhang and J.Q.Yu (2008) MADS-box genes are associated with cytoplasmic homeosis in cytoplasmic malesterile stem mustard as partially mimicked by specifically inhibiting mtETC. Plant Growth Regul. 56: 191-201.

Yang, J.H., Y. Huai and M.F. Zhang (2009) Mitochondrial atpA gene is altered in a new orf220-type cytoplasmic male-sterile line of stem mustard (Brassica juncea). Mol. Biol. Rep. 36: 273-280.

Yang, X., X.Liu, W.Lv, L.Li, Q.Shi, J.Yang and M.Zhang (2012) Reduced expression of BjRCE1 gene modulated by nuclearcytoplasmic incompatibility alters auxin response in cytoplasmic male-sterile Brassica juncea. PLoS ONE 7: e38821. doi: 10.1371/ journal.pone.0038821.

Yasumoto, K., Y. Matsumoto, T. Terachi and H. Yamagishi (2008) Restricted distribution of orf 687 as the pollen fertility restorer gene for Ogura male sterility in Japanese wild radish. Breed. Sci. 58: $177-182$.

Yasumoto, K., T. Terachi and H. Yamagishi (2009) A novel $R f$ gene controlling fertility restoration of Ogura male sterility by RNA processing of orf138 found in Japanese wild radish and its STS markers. Genome 52: 495-504.

Zhang, M.F., L.P.Chen, B.L. Wang, J.H. Yang, Z.J. Chen and H.Yutaka (2003) Characterization of atpA and $\operatorname{orf} 220$ genes distinctively present in a cytoplasmic male-sterile line of tuber mustard. J. Hortic. Sci. Biotechnol. 78: 837-841. 